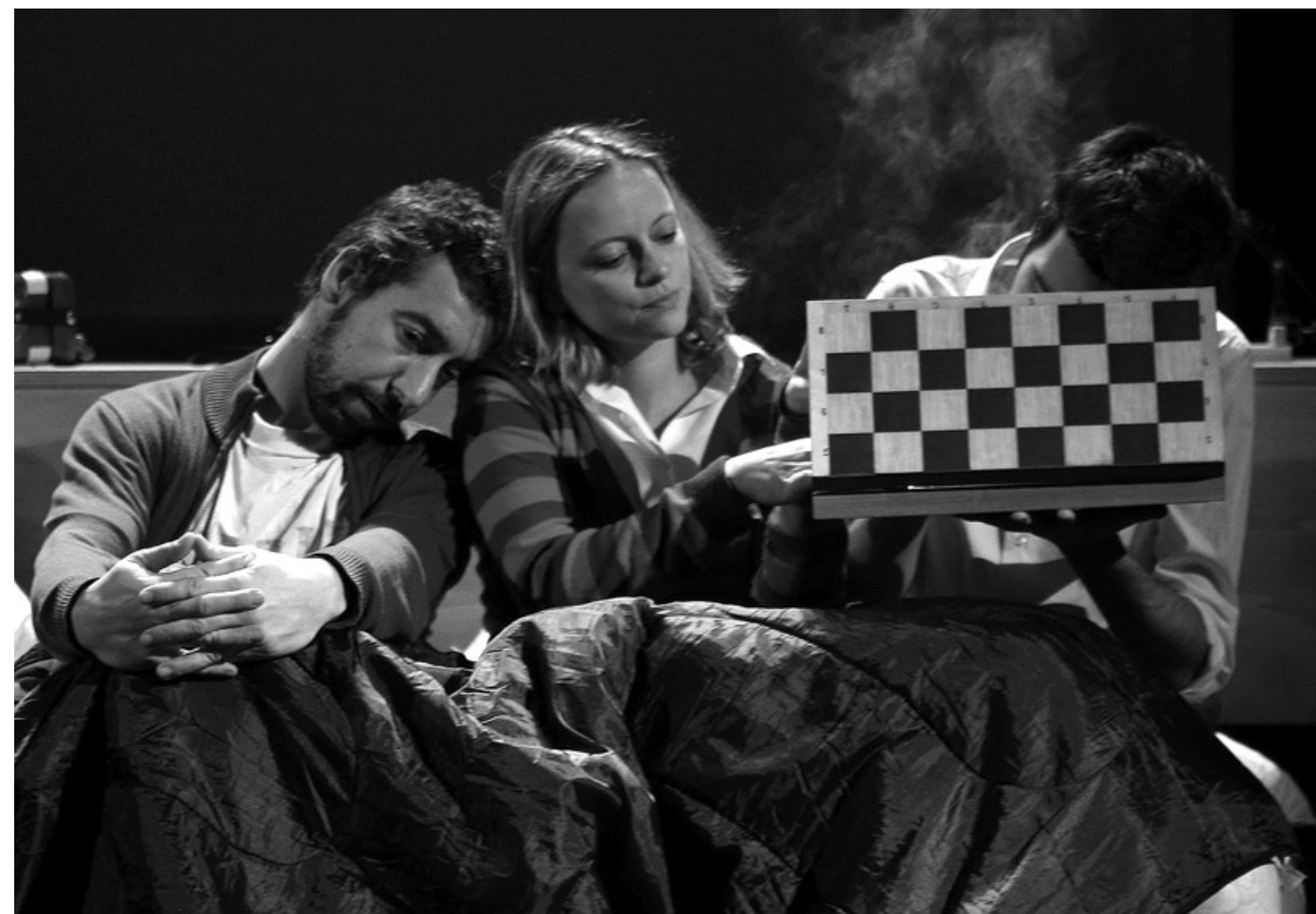

\title{
Vozes ampliadas / vidas diminuídas Uma geração ofendida
}

\section{Maria Helena Serôdio}

Titulo:Já passaram quantos anos, perguntou ele (2011). Autor: Rui Pina Coelho. Encenação: Gonçalo Amorim. Cenografia:Rita Abreu. Figurinos: Susana Sá. Adereços: João Rosário. Desenho de luz: Francisco Tavares Teles. Sonoplastia: Eduardo Brandão. Interpretação: Carlos Marques, Joana de Verona, Luis Araújo e Raquel Castro. Produção: Teatro Experimental do Porto. Local e data de estreia: Auditório Municipal de Gaia, 10 de Novembro de 2011.

A vida é o que te acontece enquanto te entreténs a fazer outros planos. John Lennon

(frase citada do programa do espectáculo, trad. minha)

\section{Atravessando texto e espectáculo, a ideia de} companheirismo e partilha - social e artística - parece ser a razão maior deste (renovado e) estimulante encontro entre Rui Pina Coelho e Gonçalo Amorim.

Um falar convergente entre ambos vinha já de outras aventuras teatrais, como foi, mais recentemente, a tradução, por Rui Pina Coelho (com Ana Raquel Fernandes), das peças de Arthur Miller - A morte de um caixeiro-viajante (2010) e Do alto da ponte (2011) - que Gonçalo Amorim encenou no âmbito da renovação que o Teatro Experimental do Porto (TEP) soube fazer nos seus próprios quadros e nos seus métodos de trabalho. E esses foram espectáculos de grande qualidade, sobretudo porque souberam aliar uma fidelidade ao texto de Miller com a revivificação da linguagem cénica. Fizeram-no reconvertendo a estética dramatúrgica milleriana num sentido que em Brecht buscou um realismo critico cenicamente mais eficiente $e_{\text {, }}$ no segundo caso, com meios audio-visuais fortemente apelativos, sintonizando a sensibilidade de uma nova geração que se sente traída pela política hoje dominante em Portugal e que procura na música anglo-saxónica o tom mais condizente com a sua indignação e revolta.

A convergência entre ambos potenciou agora uma mais ousada aventura que teve em Rui Pina Coelho o autor de uma dramaturgia própria que, assumidamente, entrelaça presente e passado, ao mesmo tempo que desenha um arco de cumplicidades e afectos entre uma geração do pós-segunda guerra mundial na Inglaterra e a que vive hoje em Portugal estes tumultuosos anos de crise sem fim à vista. Foi, de facto, a partir da peça de John Osborne Look Back in Anger (1956) que RPC resolveu reabrir em texto - e em palco - uma interpelação às possibilidades de futuro de uma juventude que traz numa mão o diploma (de licenciatura, mestrado e até

doutoramento) e, na outra, o passaporte: a ver se arranja emprego ou pronta para procurar paragens mais longinquas mas talvez mais acolhedoras.

Quando encenada em Portugal a peça de Osborne recebeu títulos diferentes: foi 0 tempo e a ira (em tradução de José Palla e Carmo) que o Teatro Experimental do Porto fez em 1967 com encenação de Fernando Gusmão, e que no ano seguinte o Teatro Experimental de Cascais montou 


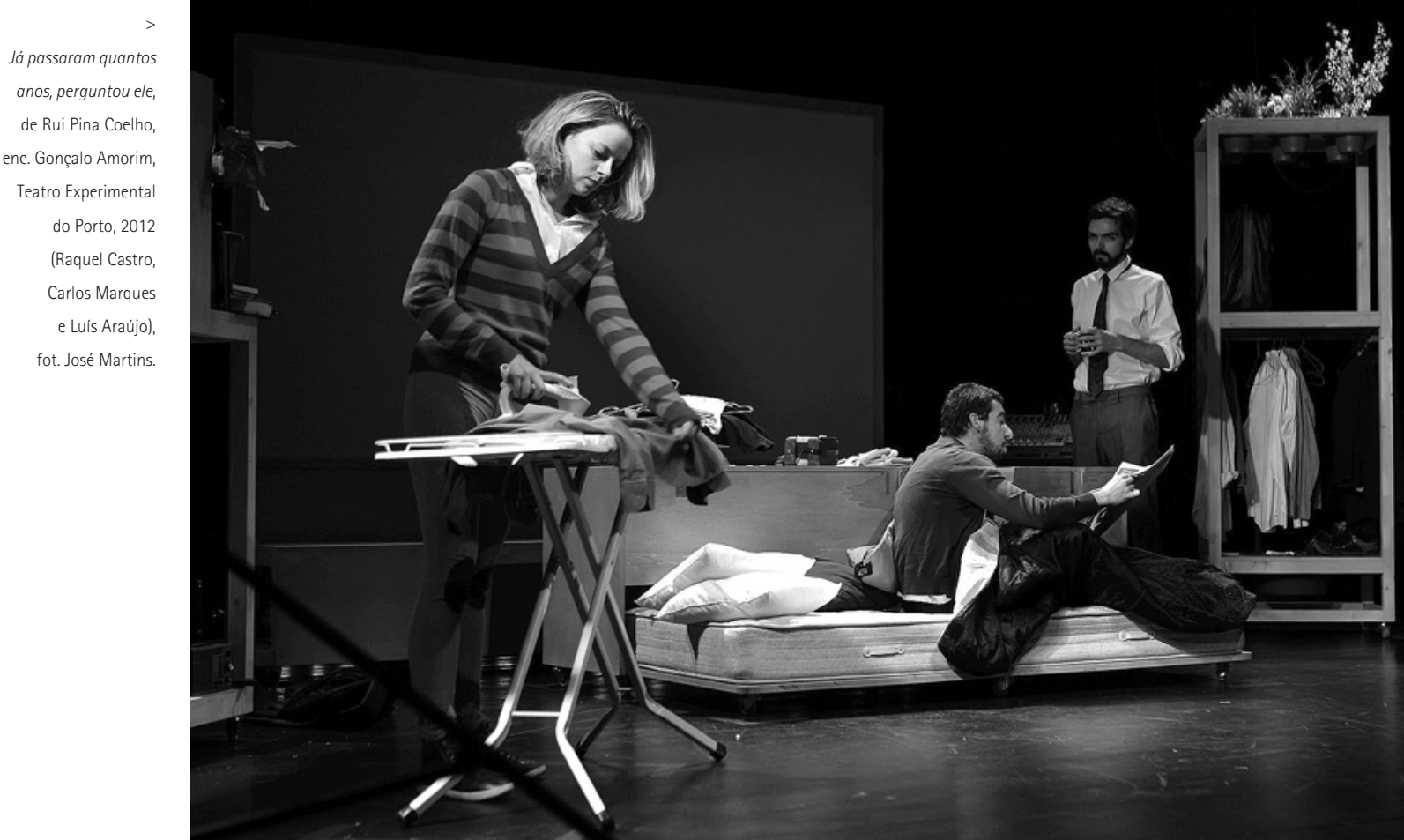

com encenação de Artur Ramos. Foi depois 0 tempo da ira, que Rui Madeira dirigiu na Companhia de Teatro de Braga em 1992, e Dá raiva olhar para trás, na versão de Gustavo Rubim que Juvenal Garcês encenou na Companhia Teatral do Chiado em 1996.

Agora, com Rui Pina Coelho, trata-se de uma reescrita inventiva que observa - mas reformula - a dramaticidade osborniana. Acolhe, de facto, em alguns dos filamentos da sua organização textual, a modalidade rapsódica que Sarrazac enunciou (2002: 225-236), envolvendo narratividade, explosão lírica, discurso directo ao público (magníficas as cenas que tomam o público como entrevistador para emprego!), arrazoados apocalíticos (mais ou menos risiveis, mas perturbadores, mesmo assim) tudo num caleidoscópio ou manta de retalhos de que, afinal, a vida é feita.

0 espectáculo desdobrava-se em preceitos coreográficos de circulação obsessiva (não longe da estética de Alain Platel), sobrepondo vozes e uma vibrante bandasonora, dando, no seu conjunto, conta da inquieta visão de uma juventude que parece ziguezaguear numa vida precária, mas que não pode demitir-se de uma vontade de viver e de se realizar no amor e no trabalho. E não faltava uma tela onde se projectavam títulos de cenas (datas de 2011, ano em que decorre a acção dramática) e outras anotações breves (citações biblicas, paráfrases de versos de músicas rock) jogando na convergência de notícias reais, ligações à internet, cenas do youtube, abrindo ainda mais aquele universo de cena à interferência do mundo exterior e marcando, assim, a impossibilidade de uma vida resguardada ou em serena e feliz intimidade.

A cenografia de Rita Abreu - feita de adereços-móveis multiusos do tipo Ikea - traz para cena a mesa da sonoplastia (que os actores manipulam) e coloca à esquerda dois dos ícones osbornianos: a tábua (e ferro) de engomar - que marcará uma agressão física, ainda que involuntária - e os peluches (urso e esquilo) que compõem a fantasia "privada" do jovem casal. Isso provocará, nesta encenação de Gonçalo Amorim, uma deliciosa cena em que ambos se mascaram com fato inteiro e, ao fundo de cena, parecem quase alhear-se dos problemas diários em curto entreacto de sonho pueril.

$\mathrm{Na}$ composição das personagens e na trama principal o texto de Rui Pina Coelho acolhe alguns aspectos importantes da dramaturgia de Osborne, como os nomes próprios - o jovem casal é Alice e Jaime, a amiga dela é Helena (e é também actriz) e o amigo dele é Cláudio (em Osborne é Cliff). Aqui também se repete a gravidez de Alice - que terminará também com um inesperado aborto - e o envolvimento afectivo de Jaime com Helena quando Alice se ausenta e eles permitem que ela fique enquanto está a trabalhar num espectáculo no TECA (Teatro Carlos Alberto), uma curiosa referência tópica em encenação que se estreava em Gaia.

Mais importante é, porém, perceber as alterações de monta que o novo texto e, em sua consequência, o espectáculo apresentam e que, indubitavelmente, aproximam mais o público de hoje da atmosfera e da problemática que a acção representa. Talvez que a diferente composição da personagem Alice possa surpreender quem recorde a passividade e bonomia (pusilanimidade, de que a acusava Jimmy) de Alison. Convergem, porém, as duas figuras nalguns pontos: têm ambas os pais ricos, e ambas sofrerão o grande abalo que representa a perda do bébé 0 que de novo Rui Pina Coelho traz é não apenas a rasura da questão política que em Osborne cavava um fosso entre a filha de um coronel que servira na İndia e o jovem Jimmy que se aproximava de um hooligan, mas sobretudo uma convergência de situação social, ainda que ela esteja com uma bolsa de doutoramento e ele desesperadamente à procura de um emprego. A impaciência e alguma agressividade de Alice (em nada parecida com a resignada paciência de Alison) é aqui o elemento novo que parece, exasperadamente, reforçar a sua importância na preparação 


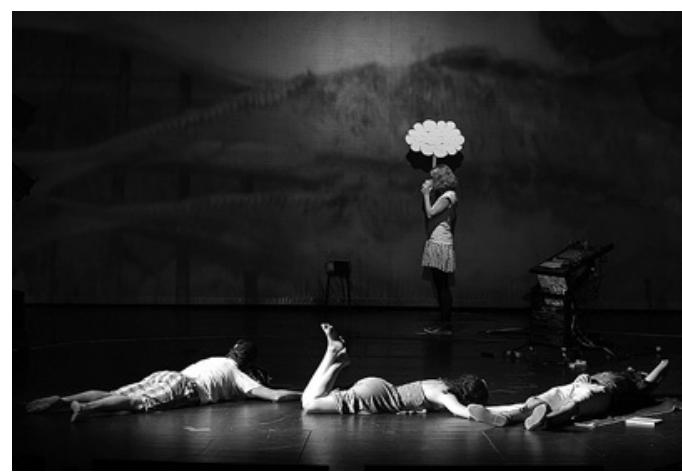

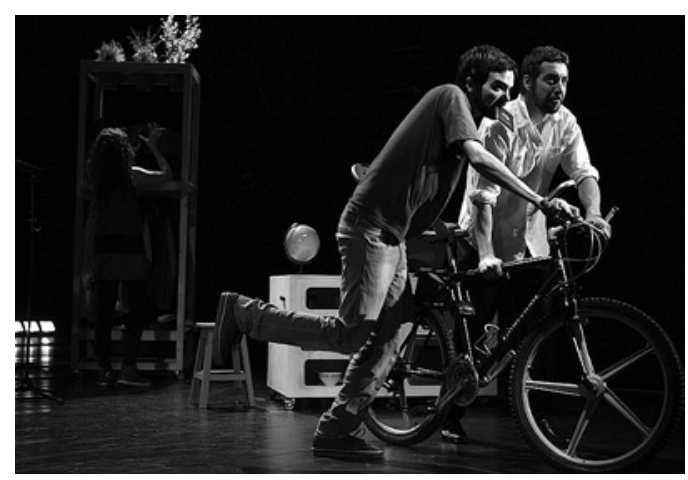

de Jaime para todas as perguntas-rasteira das entrevistas para emprego.

E se Helena Carlos aqui - como a Helena Charles de Osborne - se apresenta como figura útil apenas para permitir um companheirismo triangular relativamente irrelevante, Cláudio é redimensionado de uma forma magnífica, a que, de resto, Carlos Marques confere uma notável verosimilhança: prisioneiro permanente das noticias apocalípticas que circulam na nete que falam da morte de peixes e pássaros, numa hitchcockiana obsessão, ou como um desastrado Cyrano que se entusiasma com uma das juristas da firma de advogados, em que estagia, mas que é obrigado a rebaixar-se a moço de recados que simplesmente serve o café.

Este é, de resto, o protesto mais veemente nesta "raiva" com que olham para trás, para as promessas de que um bom curriculum académico Ihes traria recompensa de emprego digno e remuneração justa. E a imagem ícone deste espectáculo é justamente o microfone que "liga" o entrevistado a um possivel empregador (que se sentaria no lugar em que nós público estamos) e que é sinal e lugar da tortura psicológica que obriga a um cuidado paranóico para não permitir deslizes e compor, isso sim, a imagem de alguém que estará disponivel a qualquer hora, em qualquer dia - sem domingos, feriados ou mesmo férias - para trabalhar, numa absoluta e humilhante rendição ao patrão todo-poderoso.

Há sinais de uma possivel convergência na luta politica e em curtas pausas conviviais entre estes companheiros: na feitura de cartazes para uma manifestação do 25 de Abril, numa viagem de carro para a praia com picnic, e numa breve cena em que fumam erva juntos. Importante é também perceber os "mapas" simbólicos em que o elemento lúdico se alia a uma visão destrutiva, como na mesa em que as figuras parecem erguer uma cidade de plasticina facilmente destruida por um simples gesto de mão, e, durante a cena "Agosto" (ou seja, durante o

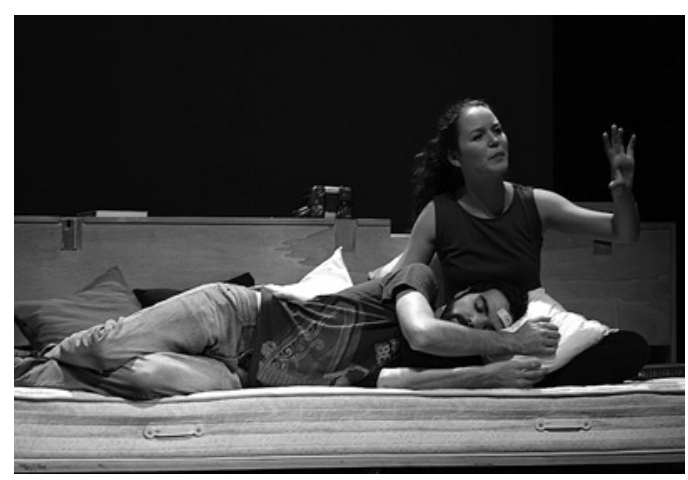

intervalo), na projecção em écran, que ocupa todo o fundo do palco, de ameaçadores jogos de computador com labirinticas perseguições e destruição de alvos, reminiscentes das suas tardes de adolescência.

E a memória de Tchekov paira nesta visitação realista à vida infeliz: "que importância é que isto tem?". Um triste e amargo desabafo e, quase irremediavelmente, a projecção no mundo desse desabar de esperanças a que se entregara antes a juventude. Mas talvez que o absurdo fim do mundo se redima em irrisória conjugação... Parece que o mundo vai acabar antes do fim da bolsa de estudo!

Por isso, no programa deste espectáculo, Gonçalo Amorim reconhece que este texto não só dá voz a uma geração - a que nasceu nos anos 70 -, como também não ignora ser essa sua vida partilhada por muitos. Pelo que era bem preciso levar ao palco uma reflexão sobre esses descaminhos da vida. Para o pôr em cena, a sua opção foi então por "um teatro de feira, dinâmico, popular,

despretensioso" e com ele ampliou cenicamente, de forma brilhante e comovente, esta declaração politicamente comprometida de Rui Pina Coelho. E foi isso que potenciou um espectáculo que, a meu ver, marcou um importante tempo do teatro para os dias de hoje.

\section{Referência bibliográfica}

SARRAZAC, Jean-Pierre (2002), o futuro do drama, trad. Alexandra Moreira da Silva, Porto, Campo das Letras. $\hat{<>}$

Já passaram quantos anos, perguntou ele, de Rui Pina Coelho, enc. Gonçalo Amorim, Teatro Experimental do Porto, 2012 (^Carlos Marques, Joana de Verona, Luis Araújo e Raquel Castro $<$ Joana de Verona Luis Araújo e Carlos Marques; $>$ Luis Araújo e Joana de Verona) fot. José Martins. 